\title{
NGHIÊN CỨU SỬ DƯNG KHÍ NÉN ĐỂ HÓA MÙ CHO HẸ THỐNG NHIÊN LIẸUU DẦU DIESEL CỦA NHÀ MÁY NHIÊTT ĐIỆN VŨNG ÁNG 1
}

\author{
Nguyễn Văn Minh, Trần Quỳnh, Hà Huy Hoàng, Mai Văn Long, Nguyễn Quốc Hương, Phạm Việt Hưng, Nguyễn Hữu Hùng \\ Tổng công ty Điện lực Dầu khí Việt Nam \\ Email: nguyenquochuong@pvpower.vn \\ https://doi.org/10.47800/PVJ.2021.09-05
}

\section{Tóm tắt}

Tại các nhà máy nhiệt điện than, dầu diesel (D0) được sử dụng trong quá trình khởi động, dừng hoạt động tổ máy hoặc đốt kèm để đảm bảo chế độ cháy ổn định. Mỗi lần khởi động lại, lò hơi sẽ tiêu tốn khoảng trên 500 tấn D0, tương đương 12 tỷ đồng.

Để tiết giảm chi phí sản suất điện và tối ưu hóa lợi nhuận, Phân xưởng vận hành Nhà máy Nhiệt điện Vũng Áng 1, Tổng công ty Điện lực Dầu khí Việt Nam (PV Power) đã nghiên cứu áp dụng giải pháp hóa mù DO bằng khí nén thay cho phương pháp hóa mù D0 bằng hơi bão hòa truyền thống. Kết quả áp dụng phương pháp mới này giúp giảm khối lượng D0 mỗi lần khởi động xuống dưới 200 tấn, góp phần giảm chi phí sản xuất điện, tối ưu hóa lợi nhuận, đặc biệt tăng tính cạnh tranh trong thị trường điện.

Từ khóa: Hóa mù dầu, vòi đốt dầu, lò hơi đốt than phun, khí nén, cháy dầu, Nhà máy Nhiệt điện Vũng Áng 1.

\section{Giới thiệu}

Hiện tại, Tổng công ty CP Điện lực Dầu khí Việt Nam (PV Power) đang vận hành các nhà máy điện:Vũng Áng 1 , Cà Mau 1 \& 2, Nhơn Trạch 1 \& 2, Hủa Na, Đăkđrinh với tổng công suất trên 4.200 MW. Việc tối ưu chi phí trong sản xuất điện là yếu tố quyết định đến lợi nhuận và giá thành sản xuất điện của các nhà máy, đến việc gia tăng sản lượng, doanh thu trong thị trường điện cạnh tranh.

Theo thiết kế ban đầu, nhiên liệu sử dụng để khởi động lò hơi của Nhà máy Nhiệt điện Vũng Áng 1 là dầu nặng (HFO - heavy fuel oil). Để đảm bảo tiêu chuẩn về phát thải theo quy định của Bộ Tài nguyên và Môi trường, Nhà máy Nhiệt điện Vũng Áng 1 đã chuyển đổi sang sử dụng DO từ năm 2018. Việc sử dụng DO thay cho HFO giúp giảm chi phí sản xuất điện do thời gian khởi động lò nhanh hơn và tiêu thụ dầu ít hơn. Tuy nhiên, việc hóa mù $\mathrm{DO}$ vẫn phải sử dụng hơi bão hòa khiến thời gian khởi động lò hơi kéo dài và chưa thực sự tiết kiệm. Ước tính mỗi lần khởi động lại, khối lượng dầu tiêu thụ cần trên 500 tấn, tương ứng với chi phí khoảng 12 tỷ đông.

Ngày nhận bài: 26/5/2020. Ngày phản biện đánh giá và sửa chữa: 26/5 - 10/6/2021. Ngày bài báo được duyệt đăng: 14/9/2021.
Để tiết giảm chi phí khởi động lại tổ máy, Công ty CP Điện lực Dầu khí Hà Tỉnh đã nghiên cứu, thử nghiệm đốt hóa mù dầu bằng khí nén trên vòi dầu của Tổ máy số 1 để so sánh, đánh giá. Trong quá trình đốt, áp suất khí nén hóa mù được điều chỉnh thông qua van điều chỉnh và đồng hồ áp suất, ghi nhận các thông số để phục vụ tính toán, phân tích. Kết quả cho thấy các vòi dầu sử dụng khí nén để hóa mù cháy ổn định hơn, có hiệu quả cao hơn so với các vòi dầu hóa mù bằng hơi. Trên cơ sở đó, Công ty $\mathrm{CP}$ Điện lực Dầu khí Hà Tĩnh đã chuyển đổi hoàn toàn hệ thống hóa mù các vòi dầu bằng hơi của Tổ máy số 1 sang sử dụng khí nén dịch vụ từ ngày 18 - 25/3/2021.

\section{Xây dựng chương trình và thực hiện chuyển đổi việc hóa mù dầu bằng khí nén}

Các nhà máy điện chủ yếu sử dụng DO là nhiên liệu dự phòng cho lò hơi, do có độ nhớt thấp, dễ vận chuyển và hóa mù. Do đó, việc sử dụng hệ thống hóa mù dầu bằng hơi nước sẽ làm tăng tiêu hao hơi tự dùng của nhà máy, tăng thời gian khởi động tổ máy do thời gian chờ đợi hơi khởi động từ lò hơi phụ trợ. Hệ thống hóa mù DO sử dụng khí nén (air atomising) sẽ tiết kiệm được lượng lớn hơi tự dùng cho mỗi lần khởi động lò hơi do sử dụng khí nén từ hệ thống khí nén chung của nhà máy. Ngoài ra, khả năng khởi động nhanh của hệ thống máy nén khí sẽ làm giảm 
được thời gian đưa các vòi đốt dầu vào vận hành, từ đó tăng tính linh hoạt của hệ thống vòi đốt dầu phụ trợ đối với quá trình thay đổi tải của lò hơi.

Các nghiên cứu của Y.H. Nazeer [1] cho thấy khả năng hóa mù của vòi đốt dầu sử dụng khí nén tốt hơn so với vòi đốt dầu sử dụng hơi hóa mù.

Vòi đốt DO sử dụng khí nén để hóa mù có ưu điểm như: Khả năng phun sương mịn, vận tốc tương đối lớn, dầu được cung cấp oxy có săn trong khí nén tăng khả năng cháy kiệt nhiên liệu, kết cấu vòi đốt tương tự như sử dụng hơi, khả năng vận hành linh hoạt, do sử dụng hệ thống khí nén sẵn có, giảm được thời gian khởi động lò và tiết kiệm hơi tự dùng.

\subsection{Lý thuyết cháy nhiên liệu lỏng}

Quá trình cháy là quá trình phản ứng hóa học giữa các nguyên tố hóa học với oxy và phát ra lượng nhiệt lớn.

Cháy hoàn toàn:

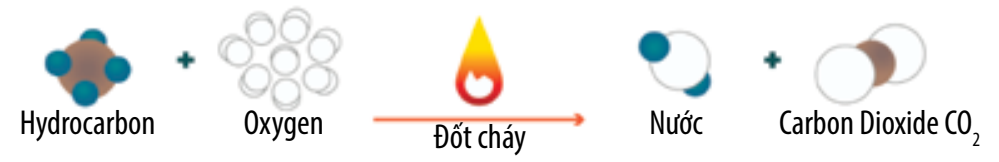

Cháy không hoàn toàn:

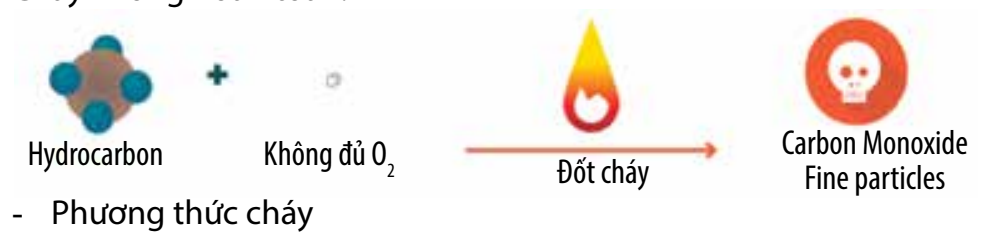

Có 2 phương thức cháy nhiên liệu lỏng: (i) Phương thức bốc hơi để cháy: Nhiên liệu lỏng đã được khí hóa và hỗn hợp với không khí theo tỷ lệ nhất định. Ví dụ trong các động cơ xăng; (ii) Phương thức phun sương: Nhiên liệu lỏng thường qua thiết bị phun sương để phun thành dòng các bụi dầu nhỏ và xung quanh các hạt sương dầu có không khí.

Trong công nghiệp, quá trình cháy nhiên liệu lỏng chủ yếu là cháy dạng phun sương.

- Các biện pháp tăng nhanh quá trình cháy nhiên liệu lỏng

+ Tăng nhanh quá trình bốc hơi của nhiên liệu lỏng

- Tăng bề mặt bốc hơi;

• Tối ưu hóa kết cấu miệng phun, đảm bảo hạt sương nhỏ và đồng đều.

+ Tăng nhanh quá trình hỗn hợp giữa hạt nhiên liệu và không khí

• Tăng cường khuếch tán, hỗn lưu và đối lưu giữa hơi dầu và không khí;

- Tạo dòng lưu chuyển xoáy;

- Phân gió sơ cấp và thứ cấp.

+ Đề phòng hoặc giảm nhẹ hiện tượng phân hủy nhiệt

- Hạn chế sự phân hủy nhiệt thành các hydrocarbon nặng (khó bắt lửa);

Quá trình phân hủy nhiệt xảy ra như sau:

$$
C_{n} H_{m} \rightarrow n C+\frac{m}{2} H_{2}
$$

Hoặc:

$$
\mathrm{C}_{n} \mathrm{H}_{m} \rightarrow \mathrm{xC}+\mathrm{yH}_{2}+\mathrm{C}_{n-x} \mathrm{H}_{m-y}
$$

• Hạn chế sự phân hủy nhiệt ở nhiệt độ cao $\left(>650^{\circ} \mathrm{C}\right)$;

- Làm mát miệng phun để đề phòng nhiệt độ gốc ngọn lửa quá cao;

- Làm cho nhiệt độ của dòng phun sương sau miệng phun thấp xuống;

- Đảm bảo hạt sương nhỏ và khuếch tán hỗn hợp tốt, tránh hiện tượng khuếch tán vào vùng nhiệt cao thiếu oxy.

- Vòi phun dầu

Căn cứ vào nguyên lý làm việc, vòi phun dầu được chia thành 2 loại:

+ Miệng phun sương dùng môi chất

Trong loại miệng phun này, động năng của môi chất phun (khí nén hoặc hơi nước) có được khi giãn nở sẽ tách giọt dầu thành các hạt nhỏ li ti gọi là "sương". Các lò hơi thường sử dụng hơi nước để làm môi chất phun sương.

Có 2 kiểu phun sương bằng hơi nước gồm phun sương hơi nước thuần túy và phun sương hỗn hợp hơi nước và cơ khí. Trong kiểu phun sương hơi nước thuần túy thì áp lực hệ thống cấp dầu không cao, thậm chí chỉ dùng độ cao của bể chứa dầu là đủ, loại miệng phun này chỉ dùng cho các lò công nghiệp nhỏ. Kiểu phun sương hỗn hợp hơi nước và cơ khí thường được dùng cho các nhà máy điện lớn. Ở đây áp suất dầu thường vào khoảng 0,5 - 2,0 Mpa, nhờ tác dụng của năng lượng dòng hơi nước và dòng dầu mà dầu được phun thành các hạt "sương".

+ Miệng phun sương cơ khí

Loại này được ứng dụng rộng rãi trong các lò hơi công nghiệp và có các loại như cơ khí ly tâm đơn giản và cơ khí ly tâm có rãnh hồi lưu dầu.

Miệng phun sương cơ khí ly tâm đơn giản có kết cấu đơn giản và lưu lượng dầu được điều chỉnh theo áp lực dầu. 


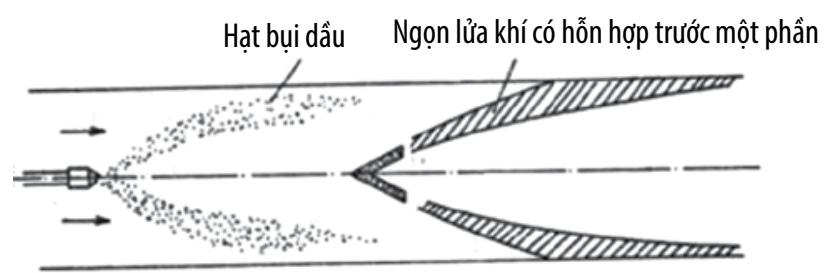

Quá trình cháy thể khí theo bốc hơi

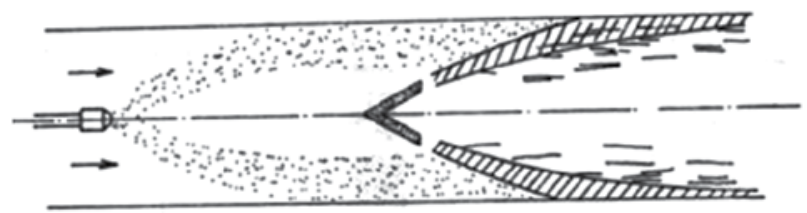

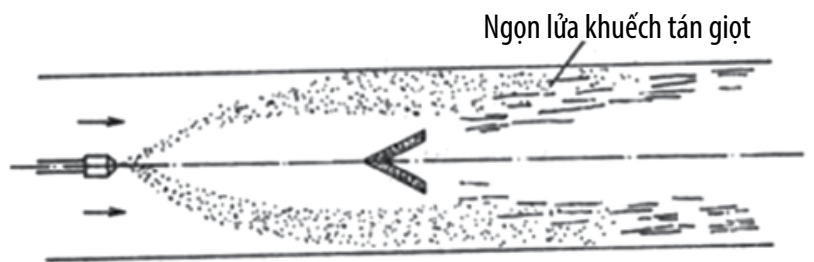

Quá trình cháy khuếch tán chùm hạt sương

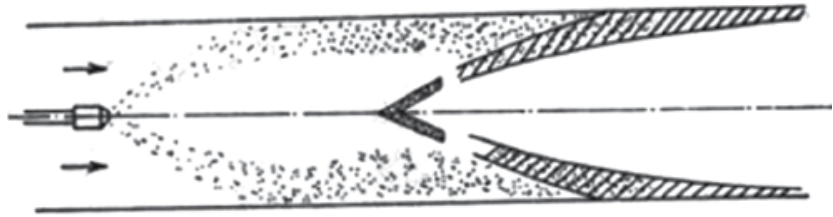

Quá trình cháy hỗn hợp có một phần hóa khí một phần hóa dạng hạt

Hình 1. Một số mô hình vật lý về quá trình cháy theo phun sương.
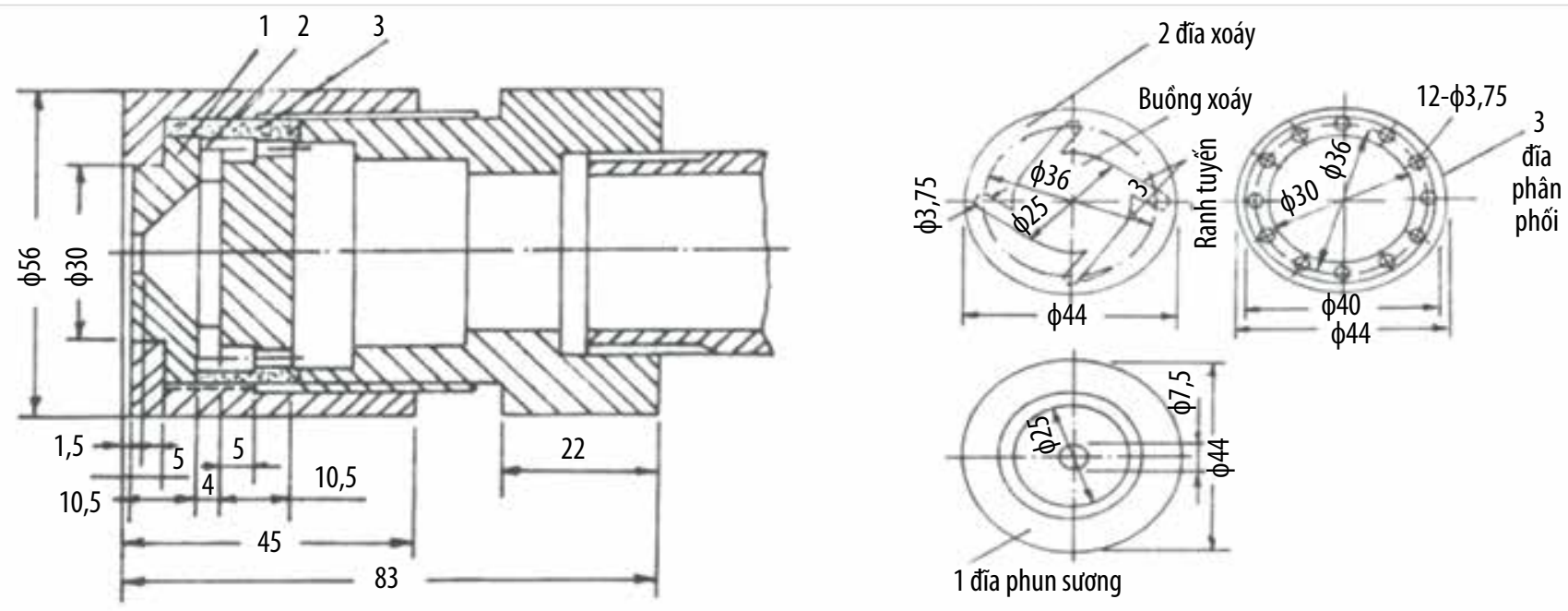

Hinh 2. Miệng phun sương cơ khíly tâm có rãnh hồi lưu dâu có thêm đường hổi lưu dâu ở đĩa phân dòng và có 2 loại: hồi lưu trong và hồ lưu ngoài.

- Các yêu cầu phối gió của thiết bị cháy dầu

+ Để tránh cho giọt dầu phân hủy nhiệt ở gốc ngọn lửa do nhiệt độ cao tác động, cần đưa vào gốc ngọn lửa lượng gió gọi là gió sơ cấp. Tổng lượng gió sơ cấp đưa vào gốc ngọn lửa và lượng gió trung tâm thông thường chiếm 15 - 30\% tổng lượng gió;

+ Dòng gió đưa vào cần phải hỗn hợp mạnh với dòng phun sương;

- Sử dụng dòng xoáy để tạo ra vùng hồi lưu khói nóng trước miệng vòi phun có kích thước phù hợp để hỗ trợ cho quá trình bắt lửa và cháy (thường kết thúc quá trình cháy trong khoảng 1 phút).

\subsection{Thiết kế hệ thống DO hiện tại của Nhà máy Nhiệt điện Vũng Áng 1}

Thiết kế ban đầu của hệ thống dầu đốt kèm sử dụng HFO và hóa mù vòi dầu bằng hơi đã được chuyển đổi thành đốt DO hóa mù vòi dầu bằng hơi. Trong quá trình sử dụng nhiên liệu $\mathrm{DO}$ hóa mù vòi dầu bằng hơi có áp suất từ 0,8 - 1,2 MPa, nhiệt độ $200^{\circ} \mathrm{C}$, đơn vị vận hành đã thử nghiệm và nhận thấy khi hóa mù bằng khí nén có một số ưu điểm nổi bật so với hóa mù dầu bằng hơi như:

- Hạn chế được sự rò xì tại mặt bích, khớp nối nhanh thường xảy ra rò xì;

- Hiệu suất cháy của DO cao hơn;

- Giảm thiểu đáng kể các dấu hiệu của khói đen cho phần đuôi lò và hệ thống lọc bụi tĩnh điện;

- Không phải dừng hệ thống lọc bụi trong quá trình khởi động lò.

\subsection{Quá trình thực hiện chuyển đổi từ hóa mù dầu bằng hơi sang hóa mù dầu bằng khí nén}

Công ty Điện lực Dầu khí Hà Tĩnh đã tiến hành xây dựng biện pháp thi công cho công tác chuyển đổi từ 

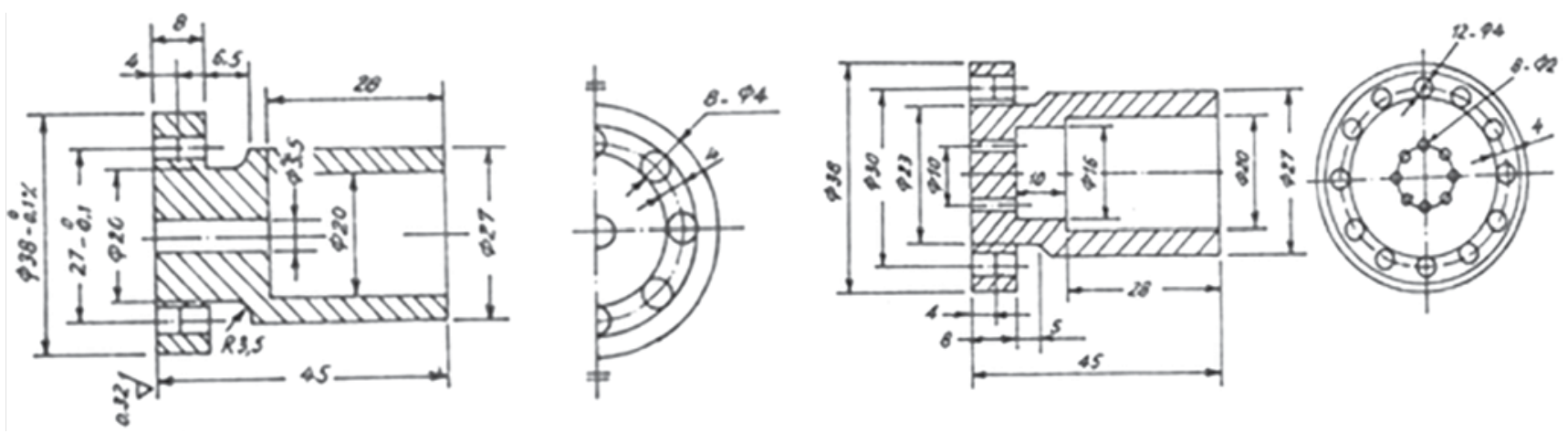

Hình 3. Miệng phun sương cơ khíly tâm có rãnh hổi lưu dâu trong và ngoài.

hóa mù dầu bằng hơi sang hóa mù dầu bằng khí nén, cụ thể:

\subsubsection{Nguyên tắc cải tiến chuyển đổi hệ thống}

Để đưa ra giải pháp công nghệ chuyển đổi hệ thống sử dụng hơi hóa mù sang dùng khí nén hóa mù tối ưu nhất, đảm bảo tính kinh tế, kỹ thuật, nguyên tắc thiết kế... hệ thống phải đạt được các yêu cầu sau:

- Đảm bảo an toàn, hiệu quả và kinh tế trong quá trình vận hành, bảo dưỡng, sửa chữa;

- Tận dụng triệt để các thiết bị hiện có nhằm giảm chi phí chuyển đổi;

- Nguyên lý điều khiển, hệ thống thiết bị đo lường, giám sát và điều khiển các hệ thống vòi đốt dầu cho các tổ máy giữ nguyên, chỉ thêm thiết bị đo lường, điều khiển áp suất khí nén.

\subsubsection{Giải pháp tính toán chuyển đổi hệ thống}

- Lưu lượng khí nén cấp đến hệ thống vòi dầu

Theo tính toán bằng công thức thực nghiệm lưu lượng khí nén cấp đến các vòi dầu như sau:

$$
Q_{r r}=1,34 \times S \times S Q R T(D P)
$$

Trong đó:

\section{$\mathrm{Q}_{\mathrm{rr}}\left(\mathrm{m}^{3} / \mathrm{s}\right)$ : Lưu lượng khí nén rò rì;}

$\mathrm{S}\left(\mathrm{m}^{2}\right)$ : Tiết diện khe hở rò rỉ, được tính theo công thức $\mathrm{S}=\left(\pi \mathrm{D}^{2}\right) / 4$, với $\mathrm{D}(\mathrm{m})$ là đường kính tương đương khe hở rò rỉ;

SQRT(DP): Căn bậc 2 của độ chênh áp khí nén trong đường ống và môi trường, áp suất tính bằng đơn vị Pascal.

1,34 là hệ số rò rỉ khí nén (theo đo lường).

Từ công thức trên, với điều kiện vòi dầu chỉ cấp khí hóa mù không cấp dầu (khi cấp dầu lưu lượng khí nén hóa mù sẻ giảm lại), tính lưu lượng khí nén thoát ra cho 1 béc phun dầu có 6 lỗ phun khí nén, mỗi lỗ có đường kính 2,5 $\mathrm{mm}$ khi áp suất khí nén duy trì ở vòi dầu với áp suất tối đa 7 bar vào buồng lửa có áp suất $-100 \mathrm{~Pa}$, như sau:

$$
\begin{aligned}
Q_{k n} & =1,34 \times S \times S Q R T(D P) \times 6=1,34 \times 3,14 \times\left(0,0025^{2}\right) / 4 \\
& \times S Q R T(700000-101325+100) \times 6=0,0305 \mathrm{~m}^{3} / \mathrm{s}
\end{aligned}
$$

Vậy tổng lưu lượng khí nén cấp đến 24 vòi dầu: $\mathrm{Q}_{\mathrm{vd}}=$ $24 \times 0,0305=0,7325 \mathrm{~m}^{3} / \mathrm{s}=2.637 \mathrm{~m}^{3} / \mathrm{h}$.

\section{- Công suất hệ thống khí nén dùng chung}

+ Hệ thống máy nén khí dùng chung gồm có 3 máy nén khí trục vít mỗi máy có công suất $50 \%$, áp suất đầu thoát 8,6 bar, lưu lượng $70 \mathrm{Nm}^{3} /$ phút $=4.200 \mathrm{Nm}^{3} /$ giờ.

+ Hệ thống đang vận hành 1 máy liên tục, 1 máy dự phòng nóng, 1 máy dự phòng nguội đáp ứng phụ tải cho 2 tổ máy.

Theo kết quả phân tích, tính toán, để tiết kiệm chi phí đầu tư ban đầu thì việc sử dụng khí nén dịch vụ cung cấp cho hệ thống hóa mù vòi dầu hoàn toàn phù hợp để thay thế hơi hóa mù.

\subsubsection{Sơ đồ đấu nối hệ thống (Hình 4).}

\subsubsection{Phương án bố trí thiết bị}

- Đường ống dẫn khí nén và các cụm van cách ly, điều khiển lắp mới được bố trí ở tầng 3 khu vực cụm van cấp hơi, cấp dầu nối từ đường ống góp cấp khí dịch vụ cho mỗi lò vào đường ống cấp hơi hóa mù hiện tại;

- Khí nén từ ống góp cấp khí dịch vụ đi vào đường ống và cụm van cách ly, điều khiển lắp mới sang ống góp cấp hơi hóa mù để cấp khí hóa mù cho các vòi dầu (hệ thống hơi hóa mù không sử dụng hơi để hóa mù các vòi dầu nữa bằng cách cô lập van cấp hơi (đóng van nguồn cấp hơi vào đường hơi hóa mù) vào đường hơi hóa mù vì đường hơi hóa mù đã có khí nén dùng để hóa mù các vòi dầu);

- Khi chuyển sang sử dụng khí nén thay thế hơi hóa mù, cần thiết phải lắp đặt các đồng hồ đo áp suất khí nén, 
áp suất dầu tại đầu vào mỗi vòi dầu để dễ dàng cho công tác hiệu chỉnh áp suất khí nén cấp vào từng vòi;

- Thay mới các van 1 chiều đường hóa mù và đường thông thổi đến các vòi dâu.

\section{Công tác thử nghiệm và đánh giá kết quả}

\subsection{Công tác thử nghiệm được tiến hành vào các ngày dừng máy trong tháng 2 - 3/2021.}

So sánh kết quả thử nghiệm khi đốt dầu sử dụng hơi hóa mù và sử dụng khí nén hóa được thể hiện trong Bảng 1.

\section{2. Đánh giá hiệu quả sử dụng khí nén hóa mù}

Sau khi chuyển đổi hóa mù các vòi dầu bằng khí nén dịch vụ, đã giải quyết được một số tồn tại như:

- Quá trình đốt dùng hơi hóa mù, dầu đốt không cháy kiệt nên vẫn có thể sinh khói đen. Khi chuyển sang dùng khí nén hóa mù, quá trình

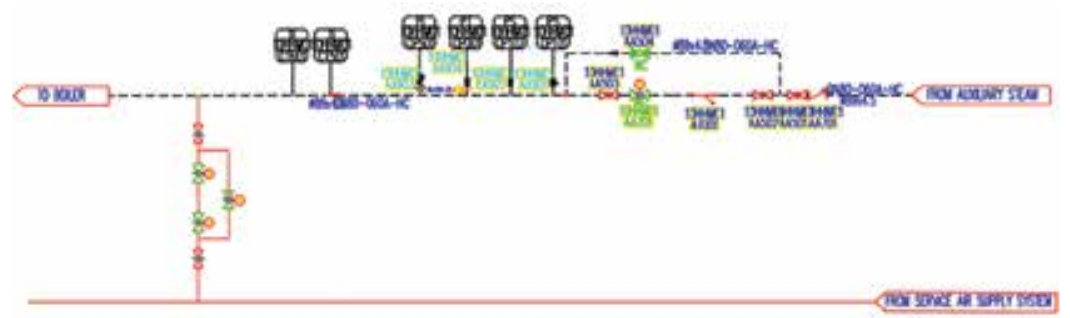

\begin{tabular}{|c|c|c|c|}
\hline \multicolumn{4}{|c|}{ Snsa \& Leco } \\
\hline sea & NWE & smoa & RNE \\
\hline 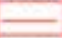 & rewo-a PPS & $T$ & Y-TPE StRuars \\
\hline$+\cdots$ & 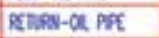 & +4 & DECO VRV \\
\hline$\cdots$ & STEW PFE & -4 & teat war vas \\
\hline 10 & PNewatc Bel-we & 8 & efctic contina vere \\
\hline$\$$ & porsser Guck STF & $\mathrm{XON}=$ & 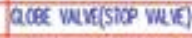 \\
\hline 0 & SEA TRAP & 8 & AECTS QCOE WLVE \\
\hline$B$ & prtucer & 9 & TREMU PONTS \\
\hline 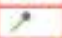 & PPNG OUnive & & \\
\hline
\end{tabular}

Hinh 4. Sơ đô đấu nối hệ thống.

Bảng 1. So sánh kết quả thử nghiệm khi đốt vòi dầu hóa mù bằng hơi và khí nén

\begin{tabular}{|c|l|l|l|}
\hline TT & \multicolumn{1}{|c|}{ Đặc tính } & \multicolumn{1}{|c|}{ Sử dụng hơi hóa mù } & \multicolumn{1}{c|}{ Sử dụng khí nén hóa mù } \\
\hline 1 & Màu ngọn lừa & Ngọn lửa màu vàng nâu và có dấu hiệu của khói đen. & Ngọn lửa cháy sáng và không có dấu hiệu khói đen. \\
\hline 2 & Lưu lượng dầu & Khoảng 1,1 tấn/giờ. & Khoảng 0,8 tấn/giờ. \\
\hline 3 & Hình ảnh ngọn lửa & & \\
\hline 4 & Thiết bị & $\begin{array}{l}\text { Vận hành ở nhiệt độ cao nên dễ bị hư hỏng thiết bị như } \\
\text { 0-ring, gasket... gây rò xì hơi, dấu, mất an toàn. }\end{array}$ & $\begin{array}{l}\text { Vận hành ở nhiệt độ môi trường nên tuổi thọ thiết bị } \\
\text { cao, ít bị hư hỏng, đảm bảo an toàn. }\end{array}$ \\
\hline 5 & Về con người & $\begin{array}{l}\text { Vận hành và bảo dưỡng khó khăn, mất an toàn. Thường } \\
\text { xuyên phải thay 0-ring, gasket do nhiệt độ, áp suất cao. }\end{array}$ & $\begin{array}{l}\text { Vận hành và bảo dưỡng dễ dàng, an toàn do nhiệt độ } \\
\text { thấp. }\end{array}$ \\
\hline
\end{tabular}

đốt ngọn lửa cháy sáng, gần như không còn khói đen, qua đó đảm bảo tiêu chuẩn môi trường trong quá trình khởi động;

- Hệ thống hơi hóa mù áp suất, nhiệt độ cao, làm nhanh hỏng các loại gioăng (như O-ring, gasket...), dẫn đến nguy cơ gây rò xì hơi, dầu, ảnh hưởng trực tiếp đến an toàn cháy nổ và không đảm bảo an toàn cho đội công tác khi xử lý rò xì, vệ sinh vòi dầu. Trong khi đó, sử dụng khí nén để hóa mù, thiết bị làm việc ở môi trường áp suất, nhiệt độ thấp, do đó giúp kéo dài tuổi thọ cho các thiết bị, ít gây rò xì, hạn chế được các nguy cơ mất an toàn và tiết giảm chi phí bảo dưỡng sửa chữa thiết bị;

- Công tác khắc phục rò xì hơi, dầu làm kéo dài thời gian khởi động gây lãng phí dầu. Do nhiệt độ thấp khi chuyển sang dùng khí nén hóa mù các vòi dầu nên công tác sửa chữa được thực hiện dễ dàng, nhanh chóng;

- Trong quá trình khởi động lò hơi chính nếu sử dụng hơi hóa mù các vòi dầu sẽ tiêu tốn lượng hơi tự dùng rất lớn, nên khi lò hơi phụ gặp sự cố mà không đảm bảo lưu lượng hơi tự dùng (trong trường hợp khởi động mà tổ máy còn lại đang ngừng) thì không thể duy trì sự cháy cho lò hơi chính. Do đó, khi sử dụng khí nén hóa mù các vòi dầu sẽ tăng độ tin cậy cho lò hơi chính; 


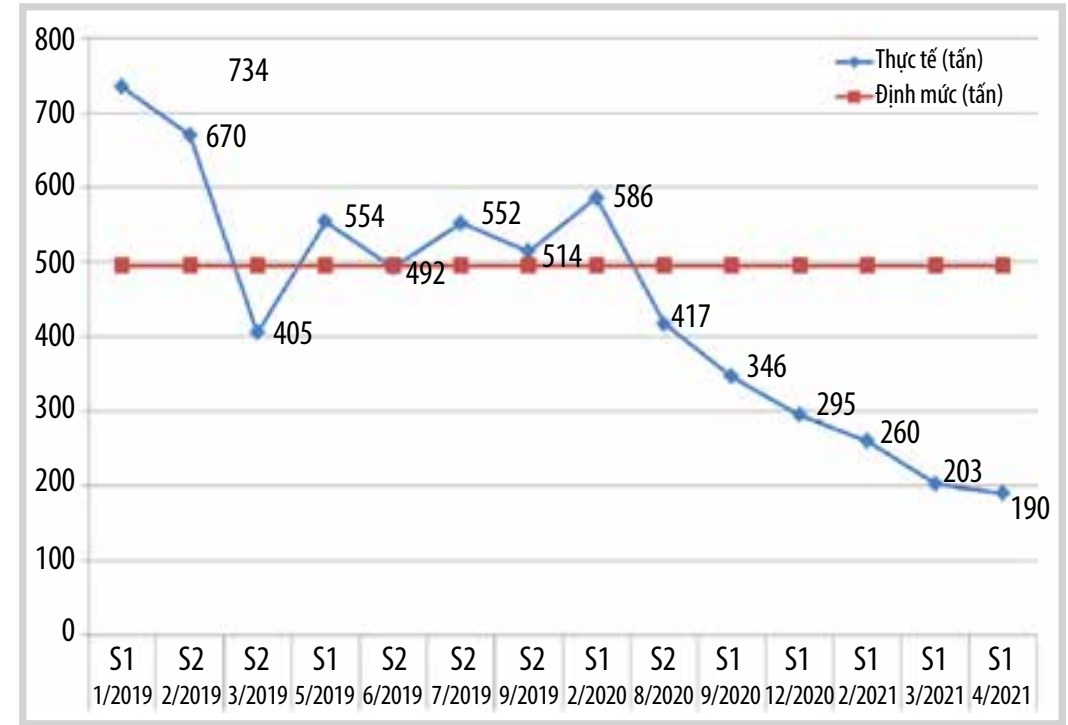

Hình 5. Kết quả chuyển đổi hóa mù D0 bằng hơi sang bằng khí nén vào tháng 3 - 4/2021.

- Khi sử dụng khí nén hóa mù thay thế hơi hóa mù, ngoài nhiệm vụ hóa mù, khí nén còn cung cấp lượng oxy cho quá trình cháy, do đó nâng cao hiệu suất đốt DO;

- Giảm thiểu nguy cơ hư hỏng các thiết bị đuôi lò như bộ sấy không khí, hệ thống lọc bụi tĩnh điện.

\subsection{Kết quả thực hiện}

Sau khi tiếp quản từ nhà thầu EPC, Nhà máy Nhiệt điện Vũng Áng 1 đã liên tục cải tiến kỹ thuật: rà soát lại quy trình vận hành của nhà chế tạo cung cấp, tiến hành thí nghiệm hiệu chỉnh, xây dựng ma trận khởi động, áp dụng thử nghiệm các công nghệ mới... Kết quả cho thấy, khối lượng DO được sử dụng tiết kiệm hơn. Đặc biệt, khi triển khai giải pháp chuyển đổi hóa mù $\mathrm{DO}$ bằng hơi sang bằng hóa mù $\mathrm{DO}$ bằng khí nén thì khối lượng $\mathrm{DO}$ sử dụng cho mỗi lần khởi động lại chỉ còn dưới 200 tấn (Hình 5).

\section{Kết luận}

Việc áp dụng giải pháp hóa mù DO bằng khí nén tại Nhà máy Nhiệt điện Vũng Áng 1 đã giúp giảm giá thành sản xuất điện, gia tăng doanh thu và lợi nhuận cho Công ty CP Điện lực Dầu khí Hà Tĩnh trong thị trường điện cạnh tranh. Kết quả khối lượng DO sử dụng giảm xuống còn dưới 200 tấn/lần khởi động, giảm khoảng 300 tấn/lần so với cách làm trước đây. Giải pháp này cũng giúp giảm phát thải nhà kính theo định hướng tăng cường hiệu suất để giảm thiểu ảnh hưởng đến môi trường.

\section{Tài liệu tham khảo}

[1] Safe Fire, "MB-1S oil igniter user manual".

[2] SH1-DHI-P1HJA-GE-M01-CTP-8201, "Commissioning procedure for inital oil firing".

[3] SH1-DHI-P1HJN-M-M01-PID-1021, "Boiler P\&ID for atomazing air system".

\title{
A STUDY ON AIR ATOMISATION FOR THE DIESEL OIL SYSTEM OF VUNG ANG 1 THERMAL POWER PLANT
}

\author{
Nguyen Van Minh, Tran Quynh, Ha Huy Hoang, Mai Van Long, Nguyen Quoc Huong, Pham Viet Hung, Nguyen Huu Hung \\ Petrovietnam Power Corporation \\ Email: nguyenquochuong@pvpower.vn
}

\section{Summary}

At coal-fired thermal power plants, diesel oil (DO) is used during the startup/shutdown of the unit or in case of unstable combustion mode. Each restart of the boiler consumes more than 500 tons of D0, equivalent to VND 12 billion.

To lower power production costs and maximise profits, the Operational Unit of Vung Ang 1 Thermal Power Plant, Petrovietnam Power Corporation have studied to apply air atomisation instead of the traditional steam atomisation for DO burners. The obtained result shows that the new method helps reduce D0 consumption to less than 200 tons/start-up, contributing to lower production costs, maximise profits and especially to increase competitiveness in the electricity market.

Key words: Oil atomising, oil burner, compressed air, oil combustion, Vung Ang 1 Thermal Power Plan. 